\title{
Research on Beijing's Industrial Structure Adjustment from the Perspective of Labor Flow
}

\author{
Miao Jin \\ 18813090983@163.com \\ Capital University of Economics and Business, Beijing, China
}

\begin{abstract}
As a leading city in the Chinese economy, Beijing has gradually transformed its industrial structure to centralized, largescale, and high-end industries. In recent years, the migrant labor force and permanent population in Beijing have increased year by year, and the population pressure has further expanded. With the adjustment of the industrial structure, the demand for labor has changed, and the labor force has moved on a large scale. This article takes Beijing as the research object and adopts a combination of qualitative and quantitative research methods to further explore the changes in Beijing's industrial structure from the perspective of labor mobility. First, by analyzing the correlation between labor mobility and industrial structure changes in Beijing, the measurement indicators of its migrant labor are determined. Secondly, by defining the measurement of industrial structure adjustment, using relevant data from the Beijing Statistical Yearbook, and analyzing the correlation between labor mobility and industrial structure changes through the analysis method of gray correlation. Finally, regarding the problems in Beijing's industrial adjustment under the background of labor mobility, it is proposed to improve the disadvantages of Beijing's industrial structure adjustment through three aspects: increasing government support, improving labor market information, and avoiding employment competition pressure, in order to provide reference for Beijing.
\end{abstract}

Published by IJRP.ORG. Selection and/or peer-review under responsibility of International Journal of Research Publications (IJRP.ORG)

Keywords: industrial structure changes; labor mobility; Beijing

\section{Research on the Correlation between Labor Flow and Industrial Structure in Beijing}

\subsection{Determination of Labor Mobility Measurement Indicators}

The changes in Beijing's total population are consistent with the changes in the total labor force, and the structure of the three industries has gradually become more rationalized and advanced. As shown in Figure 1, there is a correlation between labor mobility and changes in industrial structure. In order to facilitate the following quantitative analysis, We set Beijing's labor mobility as L (labor mobility L = total labor mobility/total population), The rationalization index of Beijing's industrial structure is $\mathrm{P}$, and the advanced index of Beijing's industrial structure is R. From the reform and opening up to 2015 in Beijing, the rationalization value $(P)$ of the industrial structure has decreased year by year, and the advanced value $(R)$ has increased year by year, indicating that Beijing's industrial structure has been continuously optimized and 
upgraded. At the same time, changes in Beijing's industrial structure have a strong synchronization and correlation with labor mobility.

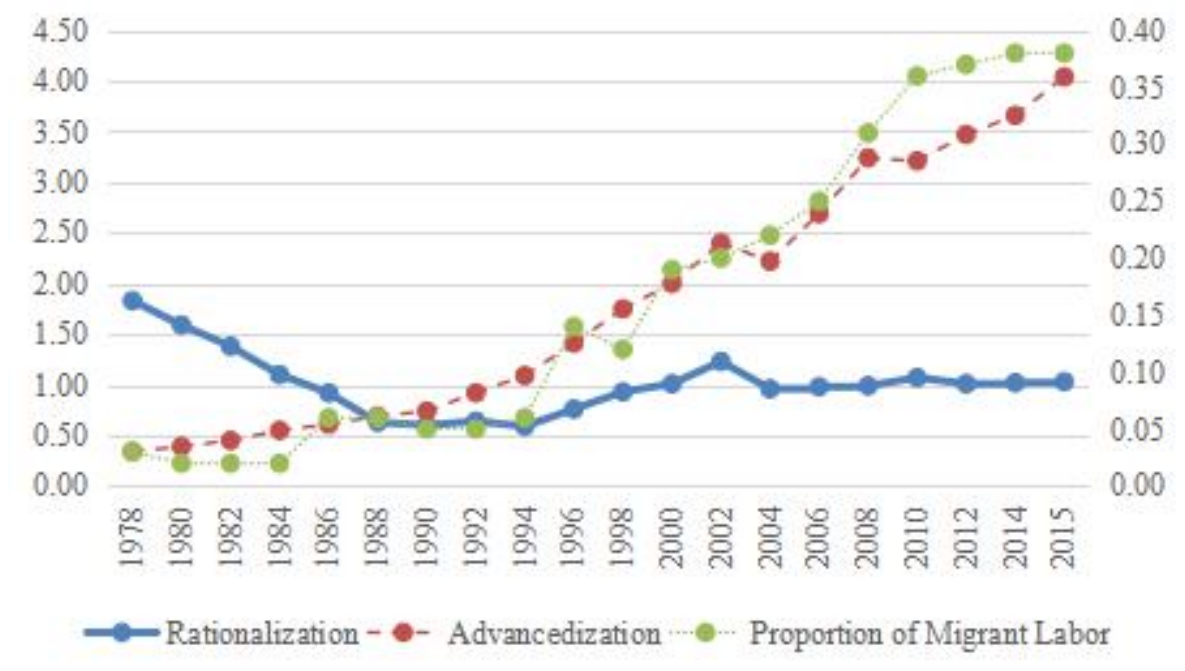

Fig. 1. Diagram of labor mobility and industrial structure changes

Source: According to the "Beijing Statistical Yearbook" over the years, the author collated and calculated.

\subsection{Definition of Industrial Structure Measurement}

Analysis on the rationalization of Beijing's three industrial structures.Two important indicators in the industrial structure are rationalization $(\mathrm{P})$ and advancedization $(\mathrm{R})$. In the optimization and upgrading of industrial structure, the former is the basis of the latter's research. This article uses the deviation coefficient of the industrial structure to illustrate the rationalization of the industrial structure. Calculated as follows:

$\mathrm{P}=\sum_{i=1}^{3}\left|\frac{Y_{i} / \mathrm{L}_{i}}{\mathrm{Y} / L}-1\right|$

In formula (1), $\mathrm{P}$ is the deviation degree of Beijing's industrial structure, $\mathrm{Y}$ is the total output value, $\mathrm{L}$ is the total number of employees, and $\mathrm{i}$ is the industry. The closer $\mathrm{E}$ is to 0 , the more reasonable the industrial structure. On the contrary, the larger $\mathrm{E}$ is, the more unreasonable.

Figure 2 shows that by the period of reform and opening up to 2015, Beijing's primary industry structure has been less rationalized, while the secondary industry structure has shown a reasonable trend year by year. Although the tertiary industry has a small fluctuation, the overall structure is good . From 1995 to 2003, Beijing's tertiary industry was relatively less rationalized than the secondary industry. From 2004 to 2015, the value of $\mathrm{E}$ was close to 0 , indicating that the higher the degree of rationalization $(\mathrm{P})$ of the tertiary industry structure in Beijing. 


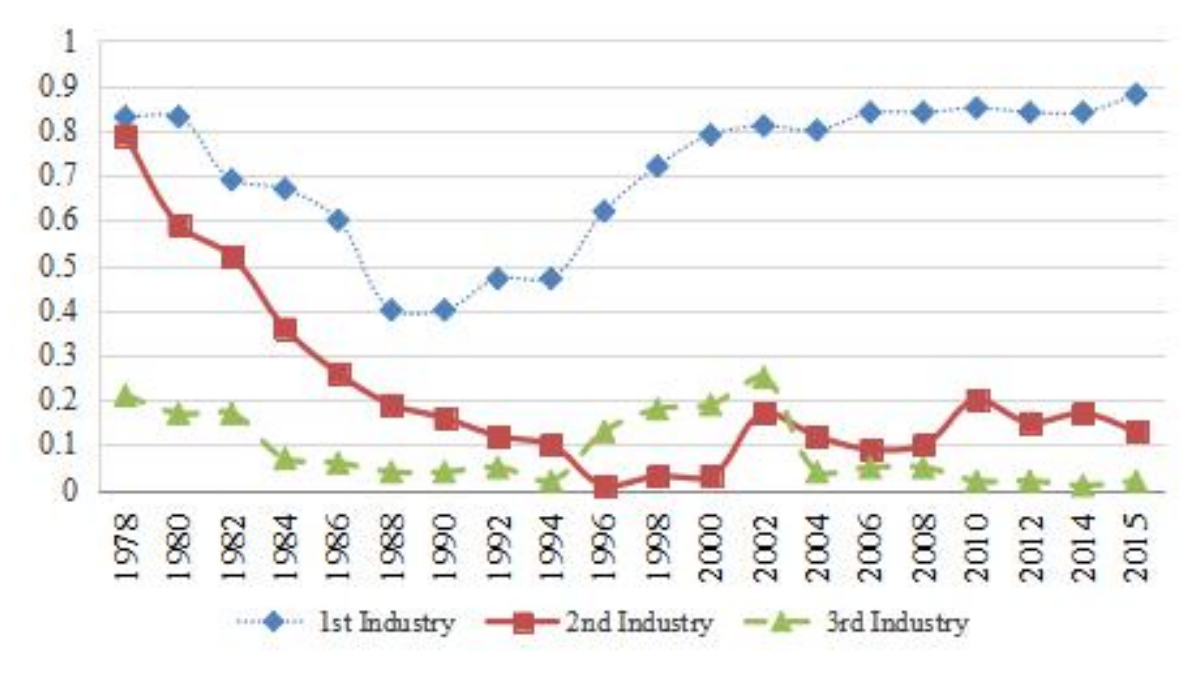

Fig. 2.The proportion of the deviation coefficient of Beijing's three industrial structure (\%)

Source: According to the "Beijing Statistical Yearbook" over the years, the author collated and calculated.

\subsection{Advanced Analysis of Beijing's Three Industrial Structure}

Two important indicators in the industrial structure are rationalization $(\mathrm{P})$ and advanced $(\mathrm{R})$. Next, we will analyze the advancement of Beijing's industrial structure and set the variables in formula (2), where $\mathrm{R}$ is the advancement of the industrial structure. is the output value of Beijing's secondary industry, is the output value of the tertiary industry in Beijing.

$$
\mathrm{R}=Y_{3} / Y_{2}
$$

It can be seen from Figure 3 that the advanced value $(R)$ of Beijing's industrial structure has increased year by year, indicating that Beijing's tertiary industry accounts for a relatively large proportion and the industry has developed rapidly. From the calculated data, it can be seen that the value (R) of Beijing's industrial structure advanced in 1978 was 0.34 . The value was greater than 1 for the first time in 1994, and reached 4.04 in 2015. The curve of rationalization and advancement in Beijing also shows a "scissors shape". However, the "scissors shape" here is different from the "scissors shape" shown by the output value and number of employees analyzed above. The rationalization value $(\mathrm{P})$ of the industrial structure here is decreasing year by year, and the advanced value $(\mathrm{R})$ is increasing year by year, which shows that Beijing's industrial structure is continuously optimized and upgraded. 


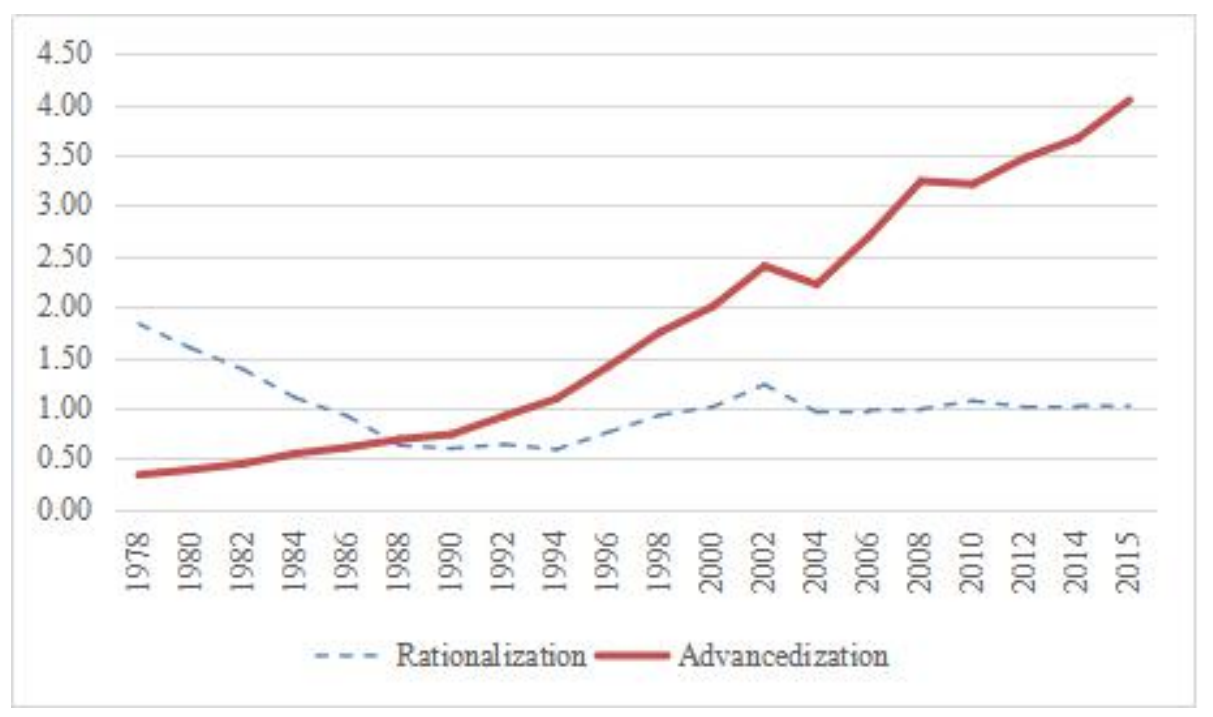

Fig. 3. The rationalization and advancement of Beijing's industrial structure

Source: According to the "Beijing Statistical Yearbook" over the years, the author collated and calculated.

\subsection{Model Establishment}

This paper adopts the research method of grey correlation to study the correlation between labor mobility and industrial structure changes (rationalization and advancedization) in Beijing. If the changes between the two variables are consistent, it indicates that there is a higher gray correlation between the two variables, and vice versa, there is a lower gray correlation.

First, we need to determine the sequence of analysis. In this article, the labor mobility of Beijing (L) is set as the reference sequence (also called the mother sequence). The rationalization of Beijing's industrial structure $(\mathrm{P})$ and the advancedization of Beijing's industrial structure $(\mathrm{R})$ are set as comparative sequences (also called sub-sequences). The correlation coefficients of rationalization, advancedization and labor mobility in Beijing's industrial structure are set to $\mathrm{Y}_{1}, \mathrm{Y}_{2}$ respectively.

$$
\begin{aligned}
& \mathrm{Y}_{1}(\mathrm{t})=\frac{\operatorname{Min}(|\mathrm{L}-\mathrm{P}|,|\mathrm{L}-\mathrm{R}|)+\rho \operatorname{Max}(|\mathrm{L}-\mathrm{P}|,|\mathrm{L}-\mathrm{R}|)}{|\mathrm{L}(t)-\mathrm{P}(t)|+\rho \operatorname{Max}(|\mathrm{L}-\mathrm{P}|,|\mathrm{L}-\mathrm{R}|)} \\
& \mathrm{Y}_{2}(\mathrm{t})=\frac{\operatorname{Min}(|\mathrm{L}-\mathrm{P}|,|\mathrm{L}-\mathrm{R}|)+\rho \operatorname{Max}(|\mathrm{L}-\mathrm{P}|,|\mathrm{L}-\mathrm{R}|)}{|\mathrm{L}(\mathrm{t})-\mathrm{R}(\mathrm{t})|+\rho \operatorname{Max}(|\mathrm{L}-\mathrm{P}|,|\mathrm{L}-\mathrm{R}|)}
\end{aligned}
$$

In formulas (3) and (4), $\mathrm{t}$ is the corresponding time, $\rho$ is the resolution coefficient, $\rho \in[0,1]$, In the next analysis, $\rho=0.5$. Max and Min refer to the maximum and minimum values taken in brackets (). 
We use the initial value method $^{\mathrm{a}}$ to process the data dimensionlessly, labor mobility (L), industrial structure rationalization $(\mathrm{P})$, and industrial structure advanced $(\mathrm{R})$. The corresponding dimensionless coefficients are L1, P1, and R1.

Through calculation, $\operatorname{Min}(|\mathrm{L}-\mathrm{P}|,|\mathrm{L}-\mathrm{R}|)=0 ; \operatorname{Max}(|\mathrm{L}-\mathrm{P}|,|\mathrm{L}-\mathrm{R}|)=15.04$; After that, the correlation coefficient and the correlation degree of the sample period are calculated for Beijing labor mobility (L), Beijing's industrial structure rationalization $(\mathrm{P})$, and Beijing industrial structure advanced $(\mathrm{R})$. Let $\mathrm{Y}_{1} 、 \mathrm{Y}_{2}$ be the correlation coefficients between the rationalization of Beijing's industrial structure and labor mobility, and the advanced industrial structure and labor mobility. $\mathrm{E}_{1} 、 \mathrm{E}_{2}$ are the correlation degree between the rationalization of Beijing's industrial structure and labor mobility, and the advanced industrial structure and labor mobility in the sample period.

$$
\begin{aligned}
& \mathrm{E}_{1}=\sum_{\mathrm{t}=1978}^{2015} \mathrm{Y}_{1}(\mathrm{t}) \\
& \mathrm{E}_{2}=\sum_{\mathrm{t}=1978}^{2015} \mathrm{Y}_{2}(\mathrm{t})
\end{aligned}
$$

Set up $\rho=0.5, \operatorname{Min}(|\mathrm{L}-\mathrm{P}|,|\mathrm{L}-\mathrm{R}|)=0 ; \operatorname{Max}(|\mathrm{L}-\mathrm{P}|,|\mathrm{L}-\mathrm{R}|)=15.04$, Putting it into formulas (3) and (4), we get $\mathrm{E} 1=0.674, \mathrm{E} 2=0.848$ 。E1、E2 $>$ resolution coefficient $\rho=0.5$, The calculation results show that there is a good correlation between labor mobility in Beijing and the rationalization and advancement of the industrial structure. E2>E1, It shows that the correlation between labor mobility and advanced industrial structure in Beijing is better than that of rationalized industrial structure.

\section{Problems in Industrial Adjustment}

\subsection{The quality of labor mobility does not match the talent needed for industrial structure upgrading}

At the current stage in Beijing, the quality of the migrant labor force is low, and the migrant labor force with higher education occupies a relatively small proportion, so most of the migrant labor force is engaged in the secondary industry that is mainly physical. At present, Beijing shows that the tertiary industry accounts for a larger proportion. According to the 2016 Beijing Statistical Yearbook, it can be seen that in the tertiary industry, the financial industry and the information software industry occupy the top two. In 2016, the migrant labor force in Beijing was $36.7 \%$. The increase of migrant labor force will increase the number of manual laborers. However, the city requires a lack of technical talents with advanced academic qualifications, and the quality of the migrant labor force does not match the talents required by the industry.

\subsection{Imperfect labor market hinders industrial structure upgrading}

The increase in migrant labor has increased the competitiveness of jobs, which has promoted the improvement of labor quality, but also intensified the pressure of competition in the labor industry. The reduction of migrant labor has led to a lack of vitality and competitiveness in the labor market, and will also affect the work efficiency of enterprises, thereby hindering the upgrading of the industrial structure. There are

\footnotetext{
${ }^{a}$ The initial value method refers to dividing each subsequent data by the first data on the basis of the same sequence. The data obtained is the multiple of each data to the first data. This sequence is called the initial value sequence.
} 
also many drawbacks in the labor market in Beijing. Incomplete information exchange, government policy restrictions and other factors will hinder the flow of talents in the labor market.

\subsection{The increase in migrant labor is not conducive to the transfer of industrial structure}

In recent years, the total population of Beijing and the number of migrant workers have increased year by year, but the quality of migrant workers has been low. The industrial structure is gradually transforming towards concentration, talent and high-end. In 2016, Beijing's tertiary industry accounted for $80.3 \%$. The gradual development of the tertiary industry can accept the influx of a part of the foreign labor force. The increase in labor mobility will restrict the transfer of labor-intensive enterprises and is not conducive to Beijing's industry. The optimization and upgrading of the structure and the development of the industrial structure of other provinces and cities.

\section{Suggestions for Beijing's Industrial Structure Adjustment}

\subsection{Increase government support}

The quality of Beijing's migrant labor force does not match the talents needed by the industry. This shows that most of the migrant labor force is mainly engaged in manual labor, and there are few high-end and technical talents. The government should introduce policies to attract more talents from higher education to Beijing, and give certain preferential conditions in terms of policy and economy, so as to better promote economic development and the optimization and upgrading of industrial structure. The Beijing Municipal Government should establish some free employment training institutions so that more migrant workers can obtain suitable jobs through basic technical training and reduce the negative impact of blind competition.

\subsection{Improve labor market information}

Beijing's current labor market information is imperfect, and along with the mismatch between the supply and demand of migrant labor, the labor market should gradually establish a system of opening corresponding positions and supply and demand information. Through the Internet and other methods, the migrant labor can better understand the employment needs of the region, and can reduce the unnecessary movement of the migrant labor, so as to find more suitable jobs.

\subsection{Try to avoid employment competition pressure}

The migrant labor force in Beijing has been increasing year by year, which also shows that Beijing is a city with huge development opportunities. The increase of migrant labor will also put a lot of pressure on competition for many jobs. At this stage in China, first-tier and second-tier cities are in a period of rapid economic development. The floating population can avoid the "Northern, Shanghai, and Guangzhou" peak floating population cities, and can also find employment options that are more suitable for themselves and their families. 


\section{References}

Bing L. The study of labor mobility and its impact on regional economic growth[J]. Procedia Environmental Sciences, $2011,10: 922-928$.

Carree M A, Thurik A R. Industrial structure and economic growth[J]. Innovation, industry evolution and employment, 1999: 86-110.

Fang X, Han X. The adjustment of employment and industrial structure under the situation of transformation of supply and demand of labor force[J]. Population Journal, 2013, 35(2): 60-70.

He D X, Yao Z Q. Effects of China's industrial structure adjustment, object of industrial optimization and policy supporting system[J]. China Industrial Economics, 2008, 242(5): 46-56.

Holstein W K, Berry W L. The Labor Assignment Decision and Application of Work Flow Structure Information[J]. Management Science, 1972, 18(7): 390-400.

Jianyong F, Lijun W, Linjie S. Industrial Concentration and the Trans-regional Flow of Rural Labor Forces[J]. Management World, 2004, 4: $22-29$.

Liu Z Y. Research on the industrial structure and the return mechanism of industrial labor force[C]//2018 International Conference on Economics, Business, Management and Corporate Social Responsibility (EBMCSR 2018). Atlantis Press, 2018.

Xinzheng L. Comparative advantages, labor force flow and industry transfer[J]. Economist, 2012, 2: 45-50.

ZHENG J, GAO Y. From Labor Flow to Regional Industrial Transfer: An Empirical Analysis on the Evolving Mechanism of Double Dual Economic Structures in Jiangsu Province [J]. Journal of Audit \& Economics, 2009, 4.

Zhu B, Zhang M, Zhou Y, et al. Exploring the effect of industrial structure adjustment on interprovincial green development efficiency in China: A novel integrated approach[J]. Energy Policy, 2019, 134: 110946. 